\title{
Espaçamento e densidade de semeadura para cultivares de sorgo granífero no semiárido
}

\author{
Carlos Juliano Brant Albuquerque $\left({ }^{1 *}\right)$; Renzo Garcia Von Pinho $\left({ }^{2}\right)$; José Avelino Santos Rodrigues ( $\left.{ }^{3}\right)$; \\ Renata da Silva Brant ( $\left.{ }^{4}\right)$; Marcelo Cruz Mendes $\left({ }^{5}\right)$
}

(') Empresa de Pesquisa Agropecuária de Minas Gerais, Caixa Postal 2248, 38402-019 Uberlândia (MG).

(2) Universidade Federal de Lavras, Departamento de Agricultura, 37200-000 Lavras (MG).

(3) Embrapa Milho e Sorgo, Caixa Postal 285, 35701-970 Sete Lagoas (MG).

(4) Universidade Federal de Uberlândia, Programa de Pós-Graduação em Agronomia, 38401-136 Uberlândia (MG).

(5) Universidade Estadual do Centro-Oeste, 85015-430 Guarapuava (PR).

(*) Autor correspondente: carlosjuliano@epamig.br

Recebido: 27/mar./2009; Aceito: 16/set./2010

Resumo

Como existem poucas informações sobre o manejo cultural do sorgo em regiões do semiárido, neste trabalho foram instalados dois experimentos, avaliando-se três densidades de plantas e três espaçamentos de cultivares de sorgo granífero, em dois anos agrícolas, na Região Norte do Estado de Minas Gerais. Em cada ano foram instalados experimentos em áreas contíguas, adotando-se, respectivamente, os espaçamentos entre linhas de $50 \mathrm{~cm}, 70 \mathrm{~cm}$ e $90 \mathrm{~cm}$ e no outro experimento foram avaliadas três densidades de semeadura, 100 mil, 140 mil e 180 mil plantas ha-1. Também, em ambos os experimentos, foram avaliadas quatro cultivares de sorgo: SHS400, 1G220, BRS310 e 0992045, em delineamento experimental de blocos casualizados no esquema fatorial $3 \times 4$, com três repetições. Com a redução dos espaçamentos entre fileiras promoveramse incrementos na produtividade de grãos e panículas do sorgo granífero, independentemente da população de plantas e cultivar avaliado. A viabilidade do aumento da densidade de semeadura é dependente da cultivar, do espaçamento e das condições climáticas prevalecentes no ano agrícola considerado. As cultivares BRS 310 e 1 G220 de sorgo granífero são promissoras para produção de grãos no semiárido da Região Norte de Minas Gerais.

Palavras-chave: Sorghum bicolor L., produtividade, grãos e arranjo de plantas.

\section{Row spacing and sowing density for grain sorghum in semiarid}

Abstract

There is little information about sorghum management in semiarid areas. Therefore, three row spacing and three sowing densities of sorghum grain cultivars were evaluated during two crop seasons, in the North of Minas Gerais State, Brazil. In each season, two experiments were carried out on contiguous areas, adopting $50 \mathrm{~cm}, 70 \mathrm{~cm}$ and $90 \mathrm{~cm}$ as row spacing in the first one and three sowing densities (100000, 140000, 180000 plants ha-1) in the second one. In both experiments, four cultivars were evaluated: SHS400, 1G220, BRS310 and 0992045. The experimental design was in random blocks, in $3 \times 4$ factorial schemes, with three repetitions. Reduction in row spacing promotes increases in grain and panicles productivity of grain sorghum. The viability of increasing sowing density depends on cultivar and row spacing and of climatic conditions prevailing in cropping year. The BRS310 and 1G220 cultivars are promising for grain production in the North of Minas Gerais State.

Key words: Sorghum bicolor L., productivity, grain, plant arrangement.

\section{INTRODUÇÃO}

A Região Norte de Minas Gerais tem uma extensão de $120.000 \mathrm{~km}^{2}$, correspondentes a $20,7 \%$ da área total do Estado de Minas Gerais. Nela há diversidades físicas bem marcantes, sendo a restrição hídrica acentuada por uma característica homogênea, o que a torna a de maior grau de aridez no Estado. Esta condição é favorável ao cultivo do sorgo, pois essa espécie pode ser substituta do milho na alimentação de ruminantes, aves e de suínos em regiôes com limitação hídrica e temperaturas elevadas.
No município de Jaíba, localizado nesta região, há diversas propriedades rurais com atividades em pecuária de corte e de leite, sendo o sorgo a principal alternativa para a produção de grãos para as criaçóes.

A produtividade média do sorgo no Brasil, em 2007, situou-se em torno de 2,15 Mg ha- ${ }^{-1}$ e, no Norte de Minas Gerais, em 1,64 Mg ha-1 (IBGE, 2009). Esse valor pode ser considerado pequeno devido às poucas informaçóes sobre tecnologias direcionadas para o semiárido do Estado.

Para se otimizar o aproveitamento do sorgo granífero, alguns produtores das regiôes do semiárido 
utilizam as panículas do sorgo (grãos de sorgo + panículas) de forma farelada, para alimentação de bovinos. As panículas são armazenadas com os grãos, em paióis de madeira ou alvenaria e, nos períodos de menos disponibilidade de grãos e forragens, são moídas e fornecidas para os animais.

Com a possibilidade do aumento da produtividade do sorgo granífero na referida região será proporcionado incremento na renda do agricultor e menor a dependência regional de cereais para o alimento das criaçôes. Entretanto, informaçóes sobre o espaçamento mais adequado entre fileiras e densidade da semeadura das cultivares modernas de sorgo são escassas na região.

É necessária definição do arranjo ideal de plantas nessas condiçōes, para que a radiação solar, os nutrientes do solo e a água sejam mais eficientemente explorados pela cultura.

Em trabalhos nos quais se avaliou o sorgo granífero semeado em diferentes arranjos de plantas com menores espaçamentos e maiores densidades foram proporcionados maiores incrementos da produtividade de grãos (MEIRA et al., 1977). Em contrapartida, BAumHardt e HoWELL (2006) não constataram influência da população de plantas na produtividade de grãos em área de sequeiro e nos menores espaçamentos também foi aumentada a produtividade de grãos.

O sorgo possui compensação de rendimento de grãos quando submetido à redução aleatória da população inicial e o componente do rendimento de grãos mais afetado pela redução aleatória da população inicial é o número de grãos por panícula (Montagner et al., 2004).

Objetivou-se, com a realização deste estudo, avaliar quatro cultivares de sorgo submetidas a três diferentes densidades de plantas e três espaçamentos, na condição climática de Jaíba, no norte de Minas Gerais.

\section{MATERIAL E MÉTODOS}

Os experimentos foram desenvolvidos nos anos agrícolas de 2006/2007 e 2007/2008. A área se situa a $12 \mathrm{~km} \mathrm{da}$ cidade de Jaíba (MG), nas coordenadas 1516’20" S e 43040'23"W, a altitude de 456 m, em Latossolo Vermelho Eutrófico.

O clima é tropical, alternadamente seco e úmido, de acordo com a classificaçáo de Köppen. Os dados sobre variaçôes na temperatura e na precipitaçáo pluvial média por decêndios, durante o desenvolvimento dos experimentos, estão apresentados na figura 1 .

Foram utilizados quatro cultivares de sorgo granífero provenientes de diferentes empresas (Tabela 1), escolhidas devido à sua ampla comercialização local, além da recomendação para cultivo na Regiāo Norte de Minas Gerais.

Os anos agrícolas 2006/2007 e 2007/2008, de acordo com os dados pluviométricos (Figura 1), caracterizaramse como "ano chuvoso" e "ano seco", respectivamente. Os experimentos foram instalados na segunda quinzena de dezembro, nos dois anos agrícolas, sob sistema de cultivo convencional em regime de sequeiro.

Em cada ano foram instalados três experimentos em áreas contíguas, adotando-se os espaçamentos entre linhas de $50 \mathrm{~cm}, 70 \mathrm{~cm}$ e $90 \mathrm{~cm}$. Para cada experimento, foram avaliadas três densidades de semeadura, 100 mil, 140 mil e 180 mil plantas ha ${ }^{-1}$ e quatro cultivares de sorgo granífero.

Cada experimento foi desenvolvido no delineamento experimental de blocos casualizados em esquema fatorial $3 \times 4$, com três repetiçóes. A parcela experimental foi constituída de quatro linhas de $5 \mathrm{~m}$ de comprimento e a área útil foi formada pelas duas linhas centrais, onde foram coletados todos os dados experimentais, antes e durante a colheita.

Para todos os experimentos, foram utilizados $350 \mathrm{~kg}$ $\mathrm{ha}^{-1}$ da fórmula 4:30:10 mais $0,5 \%$ de $\mathrm{Zn}$, com base na análise de solo. Realizou-se apenas uma adubação de cobertura com $60 \mathrm{~kg} \mathrm{ha}^{-1}$ de $\mathrm{K}_{2} \mathrm{O}$ e $80 \mathrm{~kg} \mathrm{ha}^{-1}$ de N. Para o controle de plantas daninhas foi utilizado, na pós-emergência, herbicida à base de atrazina, na dosagem de $3 \mathrm{~L}$ $\mathrm{ha}^{-1}$ do produto comercial.

A semeadura foi realizada de forma manual, uniformemente em sulcos, tomando-se como base o dobro de plantas necessárias para a obtenção das densidades desejadas. Posteriormente, foi realizado o desbaste, quando as plantas estavam com cinco folhas, para se obter a população desejada.

Foram avaliadas as características produtividade de grãos de sorgo $\left(\mathrm{Mg} \mathrm{ha}^{-1}\right)$ e produtividade de panículas $\left(\mathrm{Mg} \mathrm{ha}^{-1}\right)$.

Os dados foram submetidos, inicialmente, a uma análise de variância individual por experimento. A princípio, foram realizados os testes de aditividade dos dados, normalidade dos erros e homogeneidade das variâncias. Posteriormente, foi realizada análise de variância conjunta com os três experimentos em cada ano e outra, considerando-se simultaneamente todos os experimentos desenvolvidos nos dois anos.

Tabela 1. Características de quatro cultivares de sorgo

\begin{tabular}{llllll} 
Cultivar & Base genética & Ciclo & Porte & Panícula & Empresa \\
\hline SHS 400 & Simples & Precoce & Médio & Aberta & Santa Helena \\
\hline 1 G220 & Simples & Precoce & Baixo & Semiaberta & Dow Agroscience \\
BRS 310 & Simples & Precoce & Baixo/Médio & Semiaberta & Embrapa \\
0992045 & Simples & Precoce & Baixo/Médio & Semiaberta & Embrapa
\end{tabular}


Todas as análises, incluindo-se o estudo de regressão em função dos diferentes espaçamentos e densidades foram realizadas utilizando o programa estatístico SISVAR $^{\circ}$ (FERreira, 2000).

\section{RESULTADOS E DISCUSSÃO}

Considerando a produtividade média de gráos dos experimentos individualmente para cada ano agrícola, constatou-se rendimento equivalente a 5,09 $\mathrm{Mg} \mathrm{ha}^{-1} \mathrm{de}$ grãos em 2006/2007, superior à média do Brasil no mesmo ano, que foi $2,15 \mathrm{Mg} \mathrm{ha}^{-1}$ (IBGE, 2009). Já na safra 2007/2008, obtiveram-se produtividades bem menores com média de $1,71 \mathrm{Mg} \mathrm{ha}^{-1}$ de grãos (Tabela 2).

Além dos anos agrícolas, a produtividade dos grãos foi afetada $(p \leq 0,01)$ para as fontes de variação espaçamentos, densidades e cultivares, além das interaçôes anos $\mathrm{x}$ espaçamentos, anos $\mathrm{x}$ cultivares, anos $\mathrm{x}$ densidades, espaçamentos $\mathrm{x}$ densidades, espaçamentos $\mathrm{x}$ cultivares, densidades $\mathrm{x}$ cultivares e anos $\mathrm{x}$ espaçamentos $\mathrm{x}$ cultivares. $\mathrm{O}$ coeficiente de variaçâao (C.V.\%) foi de $12 \%$ para produtividade dos grăos. Esse valor é considerado pequeno para essa característica, segundo Pimentel (1990) e Lopes et al. (2009).

A menor produtividade de grãos no segundo ano agrícola deve-se à menor disponibilidade hídrica ao longo do ciclo da cultura. Na figura 1 constata-se que as precipitaçôes pluviais no segundo experimento foram reduzidas, com acumulado de $219 \mathrm{~mm}$ ao longo do ciclo da cultura. Já na safra de 2006/2007 foram 519 mm, durante a duração do experimento.

Nas principais áreas produtoras de sorgo do mundo a precipitação pluvial anual não é superior a $1.000 \mathrm{~mm}$. Entretanto, o importante é a quantidade de chuvas no ciclo da cultura. Para a obtençáo de safra com produtividade satisfatória deve-se ter uma precipitação, durante o ciclo da cultura, em torno de 450 a $550 \mathrm{~mm}$ (Von Pinho e Vasconcelos, 2002). Assim, no experimento desenvolvido na safra 2007/2008 não foi favorecido o cultivo do sorgo devido aos reduzidos índices pluviométricos verificados, comprometendo-se o rendimento potencial da cultura. Esse potencial pode ser maior do que $7 \mathrm{t}$ de gráos por hectare, em plantios de sucessão de culturas ou de safrinha, quando as precipitaçôes pluviais são menores (SANTos, 2003).

Considerando os fatores ambientais de regiôes do semiárido, a deficiência hídrica provocada pelos reduzidos índices de precipitações é o principal fator limitante para o cultivo de diversas espécies. O estresse hídrico é constatado quando a falta de água é excedente à absorção, devido à redução do teor de água na rizosfera das plantas (TAiz e Zeiger, 2004).

Pelos resultados analizados, evidencia-se o potencial para o cultivo do sorgo granífero em regióes com reduzidos índices pluviométricos e temperaturas elevadas em substi-
Tabela 2. Resultados médios de produtividade de grãos $\left(\mathrm{Mg} \mathrm{ha}^{-1}\right)$ de cultivares de sorgo em dois anos agrícolas

\begin{tabular}{llll} 
Cultivar & $\mathbf{2 0 0 6 / 0 7}$ & $\mathbf{2 0 0 7 / 0 8}$ & Média \\
\hline 1 G220 & $5,15 \mathrm{bA}$ & $2,12 \mathrm{aB}$ & 3,64 \\
\hline BRS 310 & $5,85 \mathrm{aA}$ & $1,38 \mathrm{bB}$ & 3,62 \\
0992045 & $4,81 \mathrm{cA}$ & $1,99 \mathrm{aB}$ & 3,40 \\
\hline SHS 400 & $4,55 \mathrm{dA}$ & $1,35 \mathrm{bB}$ & 2,95 \\
\hline Média & 5,09 & 1,71 & 3,40 \\
\hline
\end{tabular}

Médias com mesma letra minúscula na vertical pertencem ao mesmo agrupamento, de acordo com o teste de Scott-Knott. Na horizontal, médias com a mesma letra maiúscula não sáo diferentes entre si, pelo teste de $\mathrm{F}$, a $5 \%$ de probabilidade.

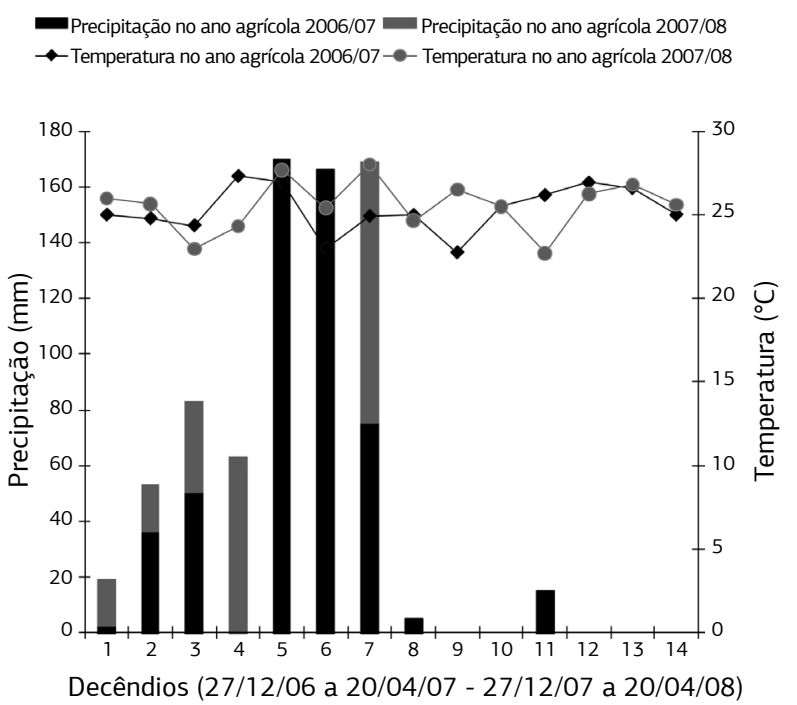

Figura 1. Dados médios de temperatura e precipitação pluvial por decêndio, em Jaíba (MG), de 27/12/2006 a 20/4/2007 e 27/12/2007 a 20/4/2008. Dados obtidos na estação meteorológica da Epamig em Jaíba (MG).

tuição ao milho. Para a obtenção de elevadas produtividades na cultura do milho são necessárias, além de precipitações pluviais superiores a $600 \mathrm{~mm}$ ao longo do seu ciclo, temperaturas noturnas não superiores a $22^{\circ} \mathrm{C}$. Em condiçóes de temperaturas noturnas elevadas, a taxa fotossintética líquida na cultura do milho é diminuída, em função do aumento da respiração com interferência no processo de produção (Fancelli e Dourado Neto, 2004).

Com essa característica é inviabilizado o cultivo do milho para elevadas produtividades no verão na Região Norte de Minas Gerais, pois as temperaturas médias diárias relatadas nos dois experimentos estavam entre $25^{\circ} \mathrm{C}$ e $30{ }^{\circ} \mathrm{C}$ (Figura 1), com temperaturas noturnas sempre superiores a $24^{\circ} \mathrm{C}$. Quando comparado ao milho, o sorgo é mais tolerante às altas temperaturas, pois sua produtividade não é negativamente afetada por temperaturas médias de até $38^{\circ} \mathrm{C}$ (Magalháes e Durâes, 2003).

Com relação à temperatura, é importante ressaltar que esta não foi limitante para o cultivo do sorgo, nos dois anos de desenvolvimento deste trabalho.

A representação gráfica da equação de regressão para a produtividade de grãos em função dos espaçamentos entre 
fileiras e cultivares, considerando-se os dois anos agrícolas, está apresentada na figura 2. Foi constatada relação linear entre a produtividade de grãos e os espaçamentos utilizados em todas as cultivares, nos dois anos de avaliaçáo e na análise conjunta. Entretanto, notou-se reduzido valor de $\mathrm{R}^{2}$ na cultivar $1 \mathrm{G} 220$, na safra 2007/2008, dificultandose $o$ ajuste da equação de regressão linear. $\mathrm{O}$ menor valor de $\mathrm{R}^{2}$ deve-se à não significância determinada entre os espaçamentos 50 e $70 \mathrm{~cm}$ para a cultivar 1G220.

É interessante destacar a produtividade da cultivar BRS 310, que foi de $6,99 \mathrm{Mg} \mathrm{ha}^{-1}$, no espaçamento $50 \mathrm{~cm}$, no primeiro ano agrícola (Figura 2). Esta produtividade pode ser considerada significativa para a condiçáo do semiárido, ressaltando-se o potencial genético desta cultivar.

Com o aumento do espaçamento na cultura do sorgo sob elevado estresse hídrico, na safra de 2007/2008, houve menos efeito na diminuição da produtividade de grãos. Em geral, com a redução do espaçamento é promovida distribuiçáo mais adequada das plantas no campo, aumentando-se a interceptação de luz e a eficiência na absorção da água no solo pela cultura.

De acordo com a equação de regressão e, considerando-se a análise conjunta dos anos agrícolas para cada cultivar, com o aumento de um centímetro entre fileiras foi proporcionado decréscimo de $30 \mathrm{~kg} \mathrm{ha}^{-1}$ na produtividade nos genótipos 1G220 e 0992045 , de $31 \mathrm{~kg} \mathrm{ha}^{-1}$ no BRS 310 e de $34 \mathrm{~kg} \mathrm{ha}^{-1}$ para o SHS 400 (Figura 2).

$\mathrm{Na}$ safra de 2006/2007, no espaçamento de $50 \mathrm{~cm}$ foi beneficiada a produtividade de grãos, sendo obtidos valores superiores a 5,5 Mg ha-1 em todas as cultivares (Figura 2). No segundo ano de experimentação, constatou-se que, no espaçamento de $70 \mathrm{~cm}$, foram obtidas produtividades semelhantes às dos experimentos instalados com $50 \mathrm{~cm}$, na maioria das cultivares. Com esses resultados
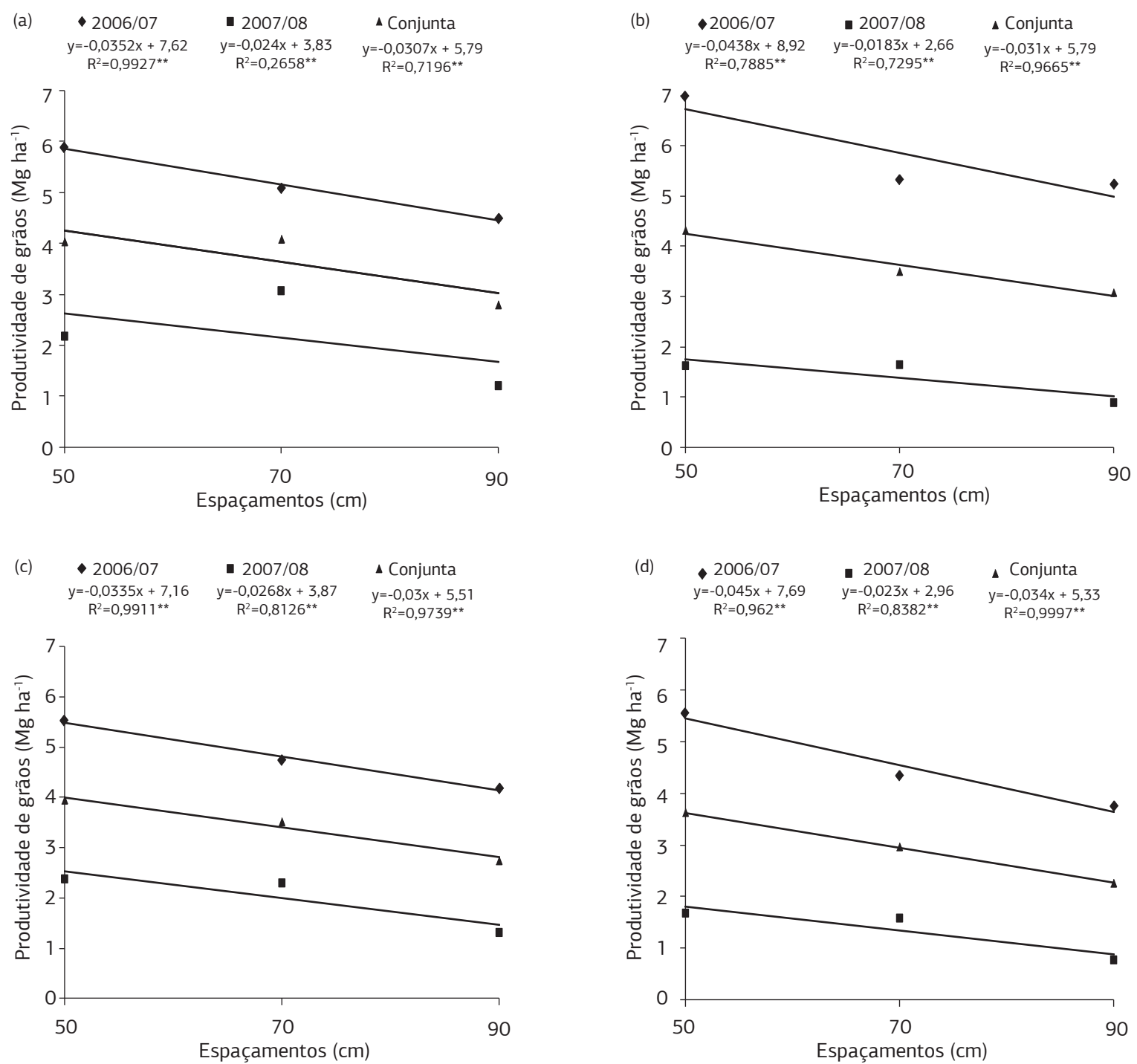

Figura 2. Representação gráfica das equações de regressão para a produtividade de grãos das cultivares de sorgo 1 G220 (a), BRS 310 (b), 0992045 (c) e SHS 400 (d), em três espaçamentos entrelinhas e em diferentes anos agrícolas. ** Significativo a 1\% de probabilidade. 
pode-se inferir que, com precipitaçôes pluviais acima de $500 \mathrm{~mm}$, ao longo do ciclo da cultura do sorgo, é favorecida a utilização de menores espaçamentos entre fileiras. É bom salientar que, apesar das maiores precipitaçóes no ano agrícola de 2006/2007, houve veranicos acentuados nos dois anos de avaliação.

Esses resultados corroboram com os obtidos por BAUmHARdt e Howell (2006), Lopes et al. (2005) e STLCHLER et al. (1997), segundo os quais as maiores produtividades do sorgo granífero são verificadas nos menores espaçamentos.

É interessante destacar que com o maior número de plantas por área pode ser favorecido o incremento de grãos em algumas cultivares. Em outros genótipos, o maior rendimento nas menores populaçóes se deve à capacidade de perfilhamento e compensação na massa dos grãos. Pode-se concluir, ainda, que alguns materiais são mais suscetíveis à competição intraespecífica, em função do arranjo de plantas.

A representação gráfica da equação de regressão, considerando-se a análise conjunta para a produtividade de grãos em função das densidades, espaçamentos e cultivar está inserida na figura 3.

Constatou-se que, ao se utilizar o espaçamento de 50 $\mathrm{cm}$, houve relação linear decrescente entre a produtividade de gráos e as densidades na cultivar SHS 400, com $\mathrm{R}^{2}$ igual a $90,6 \%$ (Figura 3a). Nesta cultivar, para cada aumento de mil plantas ha ${ }^{-1}$, ocorreu decréscimo de $14 \mathrm{~kg}$ $\mathrm{ha}^{-1}$ de grãos. Nos outros cultivares, os valores de $\mathrm{R}^{2}$ foram menores, indicativo de menor ajuste dos dados à equação proposta no espaçamento $50 \mathrm{~cm}$.

Considerando-se a equação de regressão no espaçamento $70 \mathrm{~cm}$ obteve-se reduçáo da produtividade de grãos nos cultivares BRS 310 e SHS 400 com aumento da densidade. Ao contrário, no genótipo 1G220 houve aumento linear da produtividade de grãos com a elevação do estande (Figura 3b).

Não houve significância para o efeito das densidades para produtividade de grãos na cultivar 0992045 no espaçamento $70 \mathrm{~cm}$. Esse resultado foi confirmado pelo nãoajuste dos modelos de regressão.

Foram determinadas produtividades inferiores a 3,5 $\mathrm{Mg} \mathrm{ha}^{-1}$ no espaçamento de $90 \mathrm{~cm}$ (Figura 3c). Na cultivar 1G220, houve redução da produtividade de grãos com a elevação da densidade de plantas no espaçamento de $90 \mathrm{~cm}$. Para cada aumento de mil plantas ha ${ }^{-1}$, ocorreu decréscimo de $7 \mathrm{~kg} \mathrm{ha}^{-1}$ de grãos.

Dourado Neto et al. (2003), estudando o comportamento de três cultivares de milho em três populações, também identificaram interação significativa entre cultivares x populaçóes para o rendimento de grãos, verificando, assim, que o efeito ao aumento da populaçáo de plantas é dependente da cultivar utilizada.

Ao contrário do milho, as formas de compensação do sorgo à menor população de plantas está relacionada prin-
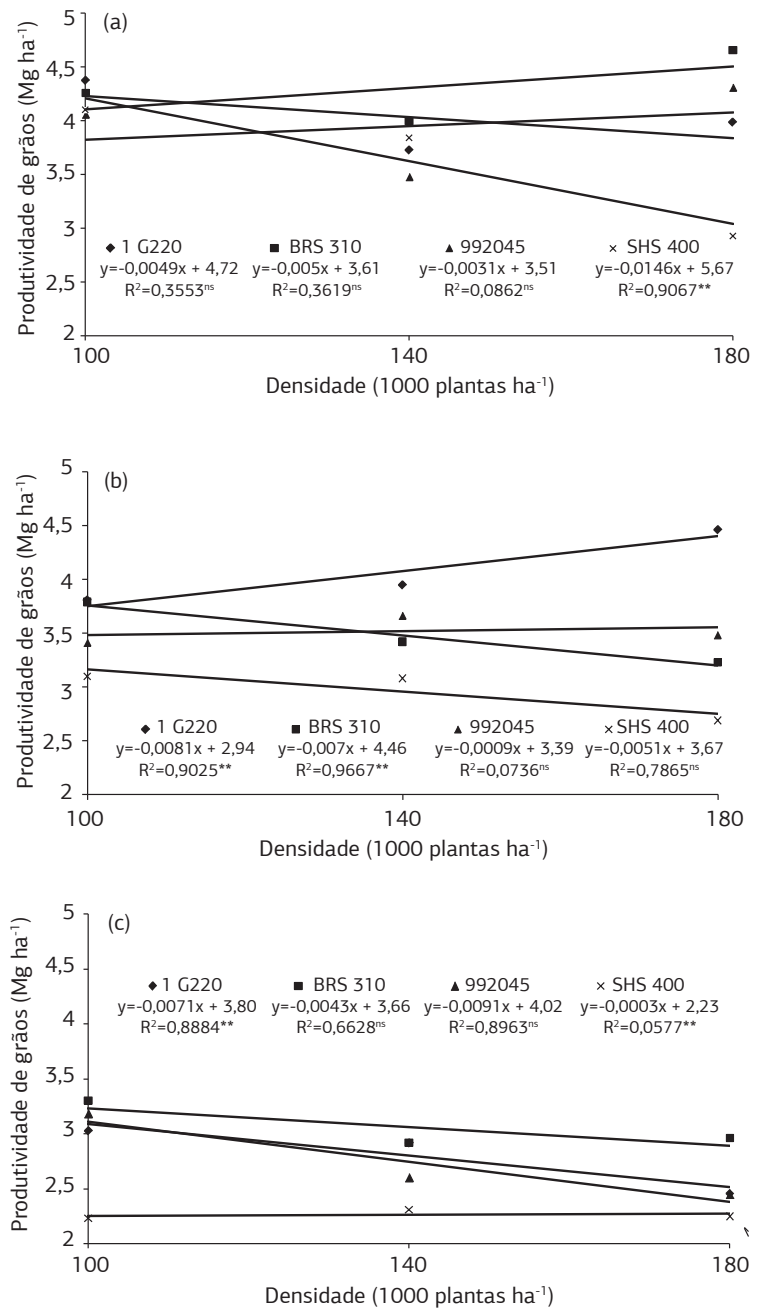

Figura 3. Representação gráfica das equações de regressão para a produtividade de grãos de quatro cultivares de sorgo, em funçáo de densidades populacionais em espaçamentos de $50 \mathrm{~cm}$ (a), 70 cm (b) e $90 \mathrm{~cm}$ (c). ** Significativo a $1 \%$ de probabilidade; ns: Não significativo.

cipalmente à capacidade de perfilhamento produtivo da espécie e ao aumento de grãos por panícula, o que ocorre principalmente em solos com elevada disponibilidade de nutrientes e restriçôes hídricas.

É necessário salientar que, no espaçamento de $50 \mathrm{~cm}$ foram proporcionadas maiores produtividades de grãos em todos as cultivares. Assim, o ajuste da populaçấo no referido espaçamento é de grande importância para a obtenção de produtividades superiores no sorgo granífero. Para o ajuste da população no referido espaçamento devese considerar, além da produtividade de grãos, o custo adicional das sementes utilizadas na semeadura.

Resultados semelhantes foram obtidos por BAUMHARDT e Howell (2006), segundo os quais, nos menores espaçamentos foi aumentada a produtividade de grãos em qualquer regime hídrico. Ainda neste trabalho, a produtividade não foi influenciada pela população de plantas no experimento desenvolvido em condição de sequeiro. Já no 
experimento irrigado, os autores relataram incrementos na produtividade de gráos com o aumento das populaçóes.

A representação gráfica das equaçóes de regressão para a produtividade de grãos em função das densidades de plantas, cultivares e anos agrícolas está inserida na figura 4. Com o aumento na densidade de semeadura nos dois anos agrícolas não foi negativamente afetada a produtividade do sorgo granífero na maioria das cultivares avaliadas, exceção do cultivar SHS 400. Notou-se, em 2007/2008, mais ajuste da equação de regressão para a cultivar SHS 400. Vale ressaltar que esse ano foi caracterizado pela maior restrição hídrica no ciclo da cultura.

Em elevadas densidades de plantas, a competição intraespecífica na cultura de sorgo também foi confirmada por Lopes et al. (2005). Estes autores obtiveram maior valor de produtividade de gráos por planta na menor densidade (100 mil plantas ha $\left.{ }^{-1}\right)$, comparada à maior densidade (220 mil plantas ha-1), nos dois espaçamentos estudados $(50 \mathrm{~cm}$ e $80 \mathrm{~cm}$ ). Ainda, com o aumento do número de plantas na linha náo foram proporcionados incrementos na produtividade de grãos por área, devido à capacidade de compensação individual das plantas de sorgo em reduzidas densidades populacionais.

Não foi constatada relação linear significativa para os ganhos de produtividade de grãos com o aumento das densidades independentemente das condiçôes climáticas prevalecentes no ano agrícola.

No Texas, EUA, Strchler et al. (1997) e Jones e JoHnson (1997) verificaram diminuição no rendimento de grãos nas maiores populações de plantas. Nesse trabalho as cultivares precoces e o maior regime hídrico foram fatores que beneficiaram o aumento da densidade. (a)
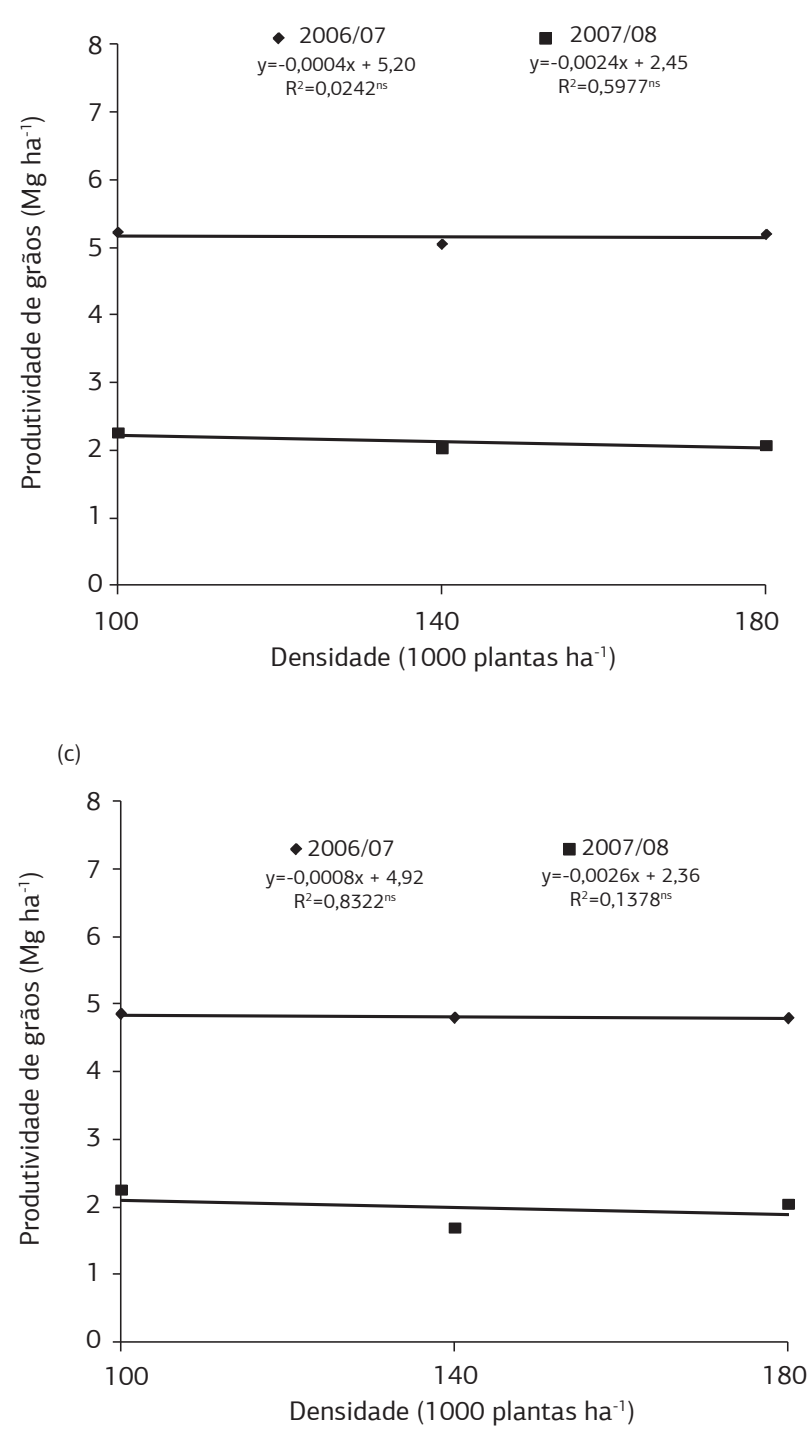

(b)
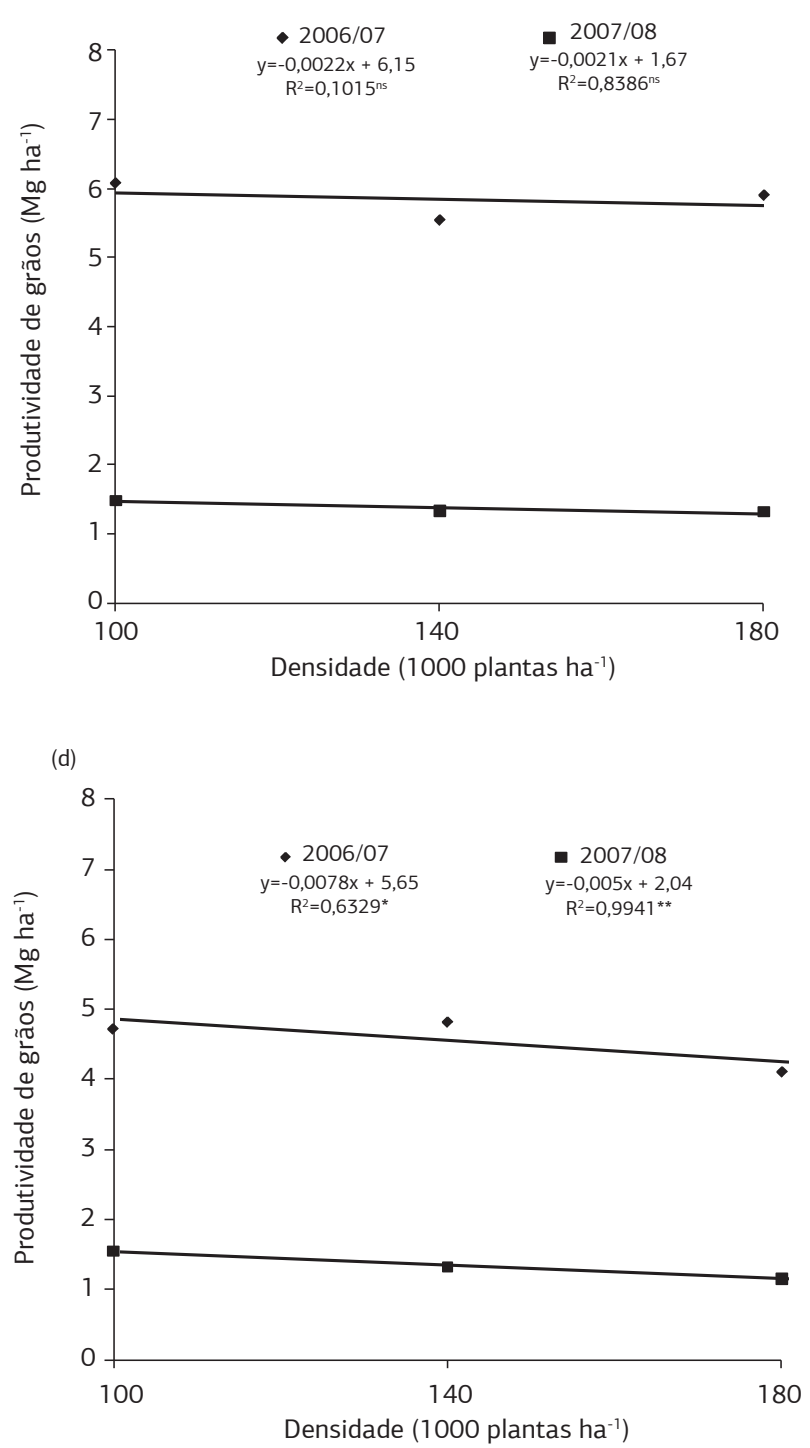

Figura 4. Representação gráfica das equaçôes de regressão para a produtividade de grãos dos cultivares de sorgo 1 G220 (a), BRS 310 (b), 0992045 (c) e SHS 400 (d), em três densidades populacionais em diferentes anos agrícolas. ${ }^{* *}$;: Significativo a 1\% e a 5\% de probabilidade respectivamente; ${ }^{\text {ns: }}$ Não significativo. 
Com isso, pode-se inferir que, com elevadas populaçôes em condiçôes de limitação hídrica não há vantagens na cultura do sorgo, devido à inibição de sua capacidade competitiva por água, luz e nutrientes. Além disso, com menor população de plantas se tem contribuição para maior número de grãos por panícula, devido à maior radiação incidente por planta (Montagner et al., 2004).

A produtividade de panículas foi afetada pelo efeito de anos, espaçamentos, cultivares, densidades e interaçóes anos $\mathrm{x}$ espaçamentos, anos $\mathrm{x}$ densidades, anos $\mathrm{x}$ cultivares, espaçamento $x$ densidades, ano $x$ espaçamento $x$ densidades, além de anos $\mathrm{x}$ espaçamentos $\mathrm{x}$ cultivares. A precisão experimental avaliada pelo coeficiente de variação (C.V.) foi considerada satisfatória, com valor de $10 \%$.

As produtividades médias das panículas foram variáveis de $8,99 \mathrm{Mg} \mathrm{ha}^{-1}$ a 10,52 $\mathrm{Mg} \mathrm{ha}^{-1} \mathrm{em} \mathrm{2006/2007} \mathrm{e}$ entre 2,73 $\mathrm{Mg} \mathrm{ha}^{-1}$ a 4,29 $\mathrm{Mg} \mathrm{ha}^{-1}$ em 2007/2008. Nos
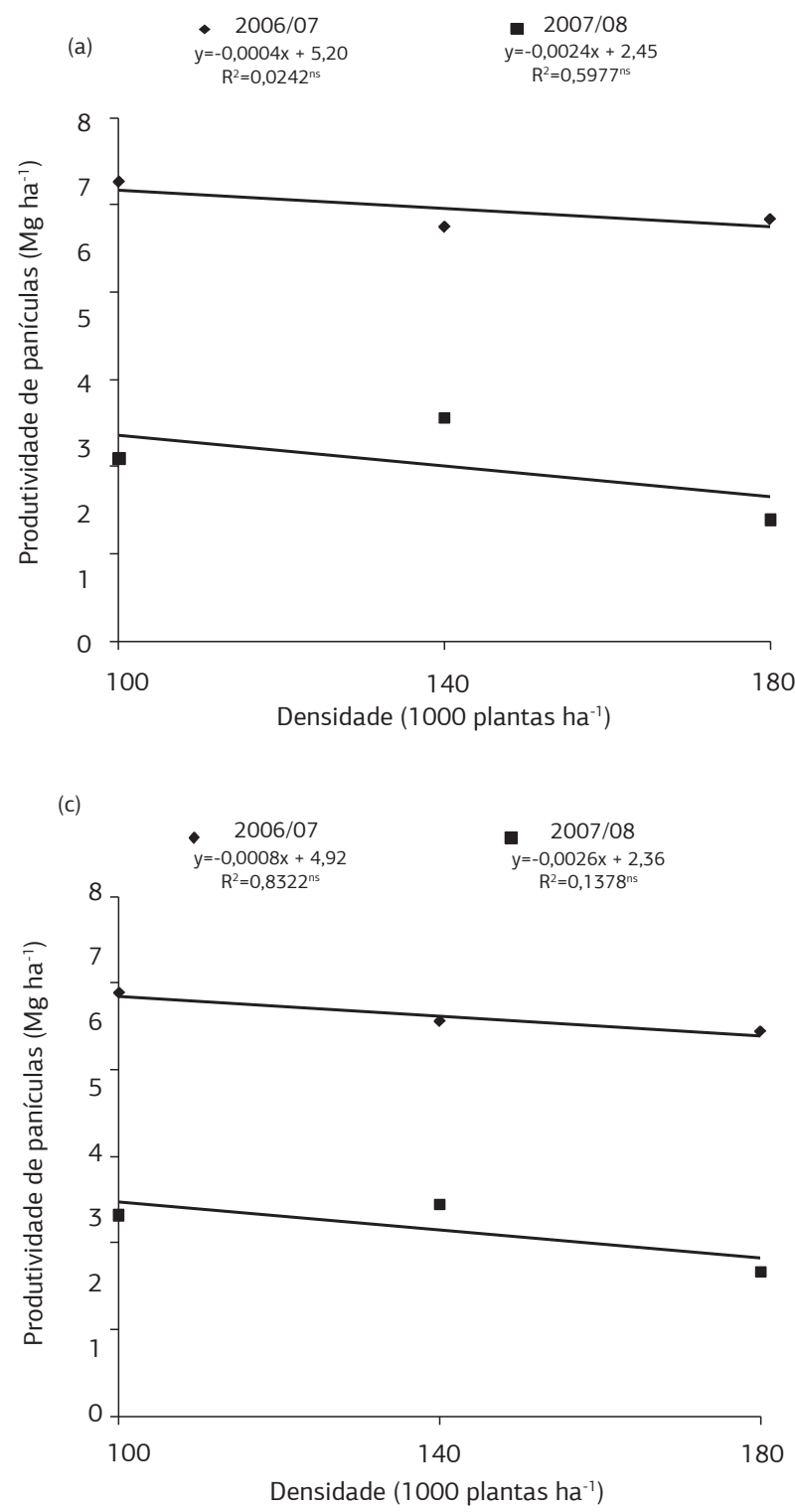

dois anos de avaliaçáo, no espaçamento de $50 \mathrm{~cm}$, foram proporcionados maiores valores de produtividade.

A representação gráfica das equaçôes de regressão para a produtividade de panículas em função dos espaçamentos, anos e cultivares está na figura 5 . Foi determinada relação linear entre a produtividade de panículas e os espaçamentos utilizados, para todos os cultivares, nos dois anos.

O pouco ajuste dos dados à equação de regressão, devido ao reduzido valor de $\mathrm{R}^{2}$ para a cultivar 1G220, em 2006/2007 e, no ano seguinte, para as cultivares BRS 310 e 0992945 , pode ser justificado pela tolerância desses genótipos às alterações no espaçamento entre fileiras (Figura 5a,b,c).

Para a cultivar SHS 400 verificaram-se valores elevados de $\mathrm{R}^{2}$ nos dois anos de avaliação. Deste modo, os aumentos das produtividades de panículas são bastante correlacionados com a diminuição do espaçamento, independentemente do ano agrícola (Figura $5 \mathrm{~d}$ ).
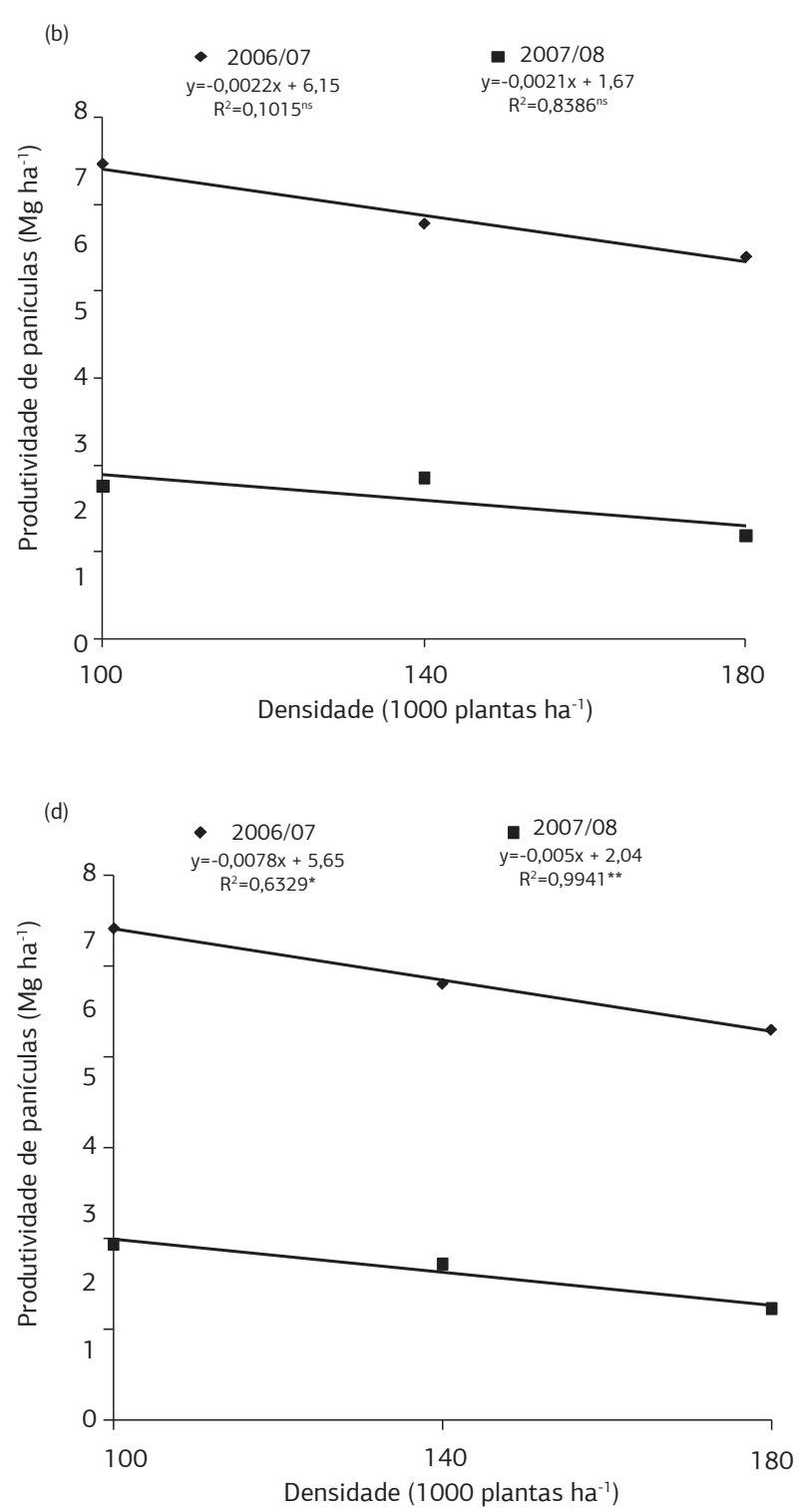

Figura 5. Representação gráfica da equação de regressão para a produtividade de panículas das cultivares de sorgo 1 G220 (a), BRS 310 (b), 0992045 (c) e SHS 400 (d), em três espaçamentos entrelinhas e nos diferentes anos agrícolas. ${ }^{* *}$ : Significativo a 1\% de probabilidade. 


\section{CONCLUSÃO}

Incrementos na produtividade de grãos e panículas do sorgo granífero são obtidos com a reduçáo dos espaçamentos entre fileiras, independentemente da população de plantas e cultivar avaliadas.

A viabilidade do aumento da densidade de semeadura é dependente da cultivar, do espaçamento e das condiçôes climáticas prevalecentes no ano agrícola considerado. As cultivares BRS 310 e 1 G220 do sorgo granífero são promissoras para produção de grãos no semiárido da Região Norte de Minas Gerais.

\section{AGRADECIMENTOS}

À FAPEMIG e ao CNPq pela concessão de bolsas de pesquisa ao primeiro e segundo autores.

\section{REFERÊNCIAS}

BAUMHARDT, R.L., HOWELL, T.A. Seeding Practices, Cultivar maturity, and irrigation effects on simulated grain sorghum yield. Agronomy Journal, v.98, p.462-470, 2006.

DOURADO NETO, D.; PALHARES, M.; VIEIRA, P.A.; MANFRON, P.A.; MEDEIROS, S.L.P.M.; RIBEIRO, M. Efeito da população de plantas e do espaçamento sobre a produtividade de milho. Revista Brasileira de Milho e Sorgo, v.2, p.63-77, 2003.

FANCELLI, A.L.; DOURADO NETO, D. Produção de milho. Guaíba: Agropecuária, 2004. 360p.

FERREIRA, D.F. Sistema de análises de variância para dados balanceados. Lavras: UFLA, 2000. (SISVAR 4. 1. pacote computacional).

INSTITUTO BRASILEIRO DE GEOGRAFIA E ESTATISTICA. Produtividade do sorgo. Disponível em: <www.ibge.gov.br>. Acesso em: 08 jan. 2009.
JONES, O.R.; JOHNSON, G.L. Evaluation of a short season. High density production strategy for dryland sorghum. Texas: USDA-ARS, 1997. p.97-101.

LOPES, S.J.; BRUM, S.; STORK, L.; LÚCIO, A.D.; SILVEIRA, T.R.; TOEBE, M. Espaçamento entre plantas de sorgo granífero: produtividade de grãos e qualificação do modelo estatístico. Ciência Rural, v.39, p.649-656, 2009.

LOPES, S.J.; STORCK, L.; LÚCIO, A.D.C.; LORENTZ, L.H.; LOVATO, C.; DIAS, V.O. Tamanho de parcela para produtividade de grãos de sorgo granífero em diferentes densidades de plantas. Pesquisa Agropecuária Brasileira, v.40, p.525-530, 2005.

MAGALHÃES, P.C.; DURÃES, F.O.M. Ecofisiologia da produção de sorgo. Sete Lagoas: EMBRAPA, 2003. (Comunicado Técnico, 87)

MEIRA, J.L.; AZEVEDO, J.T.; SILVA, J.; SCHAFFERT, R.E.; MURAD, A.M.; CARVALHO, L.J.C.B. Espaçamento e densidade do sorgo granifero. In: PROJETO Sorgo: relatório anual 72/73/74/75. Belo Horizonte: EPAMIG, 1977. p.105-121.

MONTAGNER, D.; LOVATO, C.; GARCIA, D.C. Perdas aleatórias na população inicial e sua relação com o rendimento de grãos em sorgo. Revista Brasileira de Agrociência, v.10, p.81285, 2004.

PIMENTEL, F.G. Curso de estatística experimental. 13.ed. Piracicaba: Nobel, 1990. 468p.

SANTOS, F.G. Cultivares de sorgo. Sete Lagoas: EMBRAPA, 2003. (Comunicado técnico, 77).

STICHLER, C.; MCFARLAND, M.; COFFMAN, C. Irrigated and dryland grain sorghum production south and southwest Texas. Bulletin of Texas Agricultural Extension Service, v.6048, p.1-13, 1997.

TAIZ, L.; ZEIGER, E. Fisiologia vegetal. Porto Alegre: Artmed, 2004. 722p.

VON PINHO, R.G.V.; VASCONCELOS, R.C. Cultura do sorgo. Lavras: UFLA, 2002. 76p. 